\title{
COLLABORATIVE SUPPLY CHAIN CONFIGURATIONS: THE IMPLICATIONS FOR SUPPLIER PERFORMANCE IN PRODUCTION AND INVENTORY CONTROL
}

\author{
Jan Holmstrőm ${ }^{1 \#}$, Johanna Småros ${ }^{1}$, Stephen M. Disney ${ }^{2}$ and Denis R. Towill ${ }^{2}$
}

1. TAI Research Centre, Department of Industrial Engineering and Management, Helsinki University of Technology, Helsinki, POB 9555, Fin-02015, Finland. Tel:+358 9451 5797, Fax:+35894513665, Email: jan.holmstrom@,hut.fi, johanna.smaros@hut.fi

2. Logistics Systems Dynamics Group, Cardiff Business School, Cardiff University, Aberconway Building, Colum Drive, Cardiff, CF10 3EU, UK. Tel: +44(0)29 20876083 , Fax: +44 (0)29 2087 4301, E-mail: disneysm@cardiff.ac.uk, scottd1@,cardiff.ac.uk (DR

Towill)

\begin{abstract}
The issue of how to integrate external collaboration with internal processes is identified as a gap in the body of supply chain knowledge. The question is how to link external sources of information into the vendor production and inventory control process when the same level of detailed information cannot be obtained from all of its supply chain partners. The objective of this paper is to present a simple framework to guide the research on the barriers to external and internal integration in different collaborative supply chain configurations. Five different supply chain configurations will be discussed and compared in the paper. These configurations are distinguished by the differences in the control of material flows; information flows; and the decision taking processes. Each configuration is discussed in terms of industrial practice to highlight from a supplier perspective the opportunities and challenges to benefit in production and inventory control.
\end{abstract}

\section{KEYWORDS:}

Supply chain management (SCM), demand visibility, information sharing, vendor-managed inventory (VMI), production planning, inventory control

\section{INTRODUCTION}

Changing how and when a supplier delivers a product can transform a business model (Hoover et al, 2001). Vendor Managed Inventory (VMI) is one such mechanism that has been popular in recent literature (Holmström, 1998; Sabbath et al, 2001). Unfortunately however, practical examples of how VMI and other collaborative supply chain configurations can be precisely used to improve production planning and inventory control in supplier firms are difficult to find in industry. For example, the scope of standard solutions for VMI in commercial Enterprise Resource Planning applications does not include recommendations for linking the replenishment collaboration to production and inventory control.

By using Distribution Requirements Planning (DRP) (Bookbinder and Heath, 1988) in the supply chain it is possible to link replenishment collaboration with the production and

${ }^{*}$ Corresponding Author 
inventory control (PIC) decision of the supplier in principle. This requires reliable and timely sales, inventory and forecast information from all the inventory locations in the distribution network. Even within the more limited scope of a company controlled distribution network, a major obstacle to DRP has been the difficulty to obtain reliable forecasts from individual inventory locations.

The issue of how to integrate external collaboration with internal processes is seen to be a gap in the body of knowledge (Lapide, 2001). The open question is how to link external sources of information into the vendor's production and inventory control processes when the same level of detailed information cannot be obtained from all of the distribution channels (Stank et al, 2001). Considering the high hopes (Lee et al, 1997, Mason-Jones and Towill, 1997, and $\mathrm{Yu}$ et al, 2000) predicted from the benefits of utilising demand visibility for improving supply chain efficiency this gap is in a surprisingly critical area for enabling the success of supply chain management. A barrier to progress is seen to be the evidence that optimisation of the interests of individual firms mitigate against supply chain collaboration (Cachon and Lariviere, 1999).

The research question to be answered in this paper is the following: what are the possible external collaboration mechanisms and how may they be integrated with supplier internal production and inventory management processes?

\section{CLASSIFICATION OF COLLABORATIVE SUPPLY CHAIN CONFIGURATIONS}

Reducing uncertainty via transparency of information flow (Geary et al, 2002) is a major factor in matching collaboration type to system objectives. To guide our investigation on what makes it difficult to link external and internal integration a simple framework can be defined of the alternative collaborative supply chain configurations. In this paper five different supply chain configurations will be discussed and compared. These are shown in Table 1. These configurations are distinguished by the differences in the control of material flows; information flows and the decision taking processes. Each configuration will be discussed in terms of industrial practice to highlight from a supplier perspective the opportunities and challenges to benefit in production and inventory control.

\begin{tabular}{|c|c|}
\hline Configuration & Description of collaborative or vendor managed functions \\
\hline Type 0 & Traditional Supply Chain \\
\hline Type I & Replenishment Only \\
\hline Type II & Replenishment and forecasting \\
\hline Type III & Replenishment, forecasting and customer inventory management \\
\hline Type IV & Replenishment, forecasting, customer inventory management and \\
distribution planning
\end{tabular}

Table 1. Supply chain configurations defined for investigating implementation problems

\section{CHALLENGES OF PRODUCTION AND INVENTORY CONTROL IN THE SUPPLY CHAIN}

Magee (1958) recognised the challenge in developing an effective process solution for production and inventory control that takes into consideration both the supplier's and customer's interests. Magee also states that the both parties interests may be satisfied by defining the responsibilities in a particular way. Quoting directly from his book,

"It is possible to restate the question slightly differently and thereby reach a solution. For example, the user has to be sure that the material will be there when needed. He has 
corresponding responsibility to state what his maximum and minimum requirements will be. Once these limits are accepted as reasonable, the supplier has the responsibility of meeting demand within these limits, making whatever use he can of the flexibility that (holding the) inventory provides. Thus both (players) have a share in the responsibility for and control over a stock unit. One specifies what the maximum and minimum demands on the stock unit will be; the other has the responsibility of keeping the stock unit replenished but not overloaded as long as demand stays within the specified limits".

This way of redefining the responsibilities together with the sharing of information on the true supply chain state can contribute to overcoming divergent interests. But how can this be carried out in practice, when a supplier has 100's of SKUs and 100's of customers to consider? What are the challenges of increasing the use of customer information in the production and inventory control decision when moving from Type $O$ to Type IV in the collaboration typology? The different types differ in the external information sources used for production and inventory control. First only customer orders are included, later also the customer inventory situation and finally the distribution requirements.

\section{TYPE 0: TRADITIONAL SUPPLY CHAIN}

In Type 0 supply chains the only information that is available to the supplier is a purchase order. Purchase orders often cause the bullwhip problem (Lee et al., 1997). This happens when the variance of orders increases as demand moves up chain. This variance amplification causes a lot of unnecessary costs in supply chains. For example, it has been estimated that the economic consequences of the bullwhip effect can be as much as $30 \%$ of factory gate profits, Metters (1997). The negative effects of bullwhip problem have been further summarised by Carlsson and Fullér (2000) as follows;

- Excessive inventory investments throughout the supply chain to cope with the increased demand variability

- Reduced customer service due to the inertia of the production/ distribution system

- Lost revenues due to shortages

- Reduced productivity of capital investment

- Increased investment in capacity

- Inefficient use of transport capacity

- Increased missed production schedules

It is possible to redesign the replenishment order to remove bullwhip, that is, to smooth the ordering pattern, but this often (but not always) comes at the cost of either extra inventory or lower availability unless care is taken (Disney, Farasyn, Lambrecht, Towill, and Van de Velde, 2003).

We have developed a set of "water tank" models of each of the 5 categories of collaborative arrangements in supply chains. The Type 0 traditional supply chain water model is shown below in Figure 1. We can see that there are two ordering decisions ("ball-cocks") in series in this two level supply chain. Water represents inventory and the flow of water represents sales of products. For example, a consignment stocking arrangement is a still a Type 0 supply chain as the only thing that changes is the ownership of the inventory. The same decisions are being made based on the same information as in a traditional supply chain. 


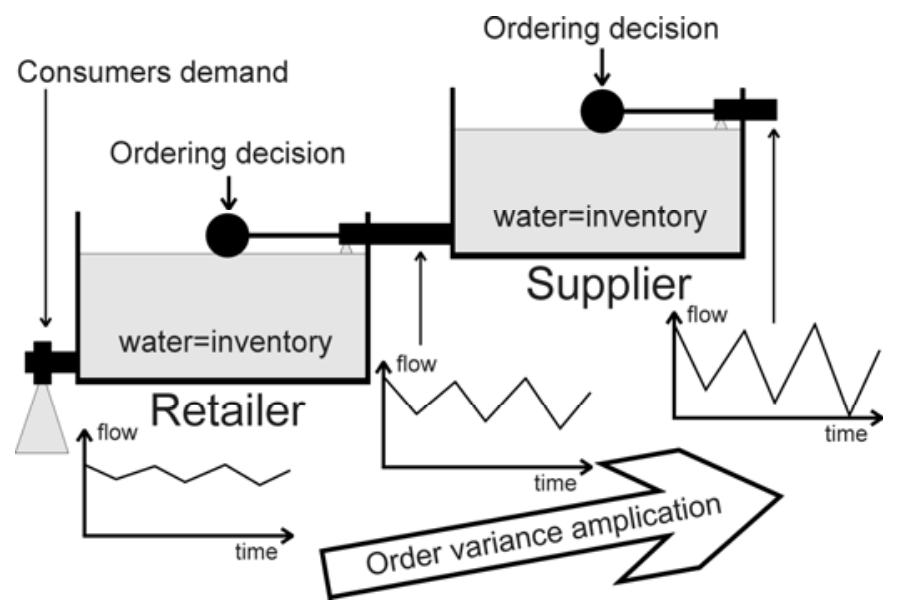

Figure 1. A Type 0 supply chain conceptualised as a water tank model

\section{TYPE I: REPLENISHMENT ONLY}

In Type I relationships the customer has given the responsibility for placing replenishment orders to the supplier. Using the customer information the inventory investment needed to maintain customer service levels can potentially be reduced. But in effect the supplier has a dedicated process to generate exactly the same replenishment orders based on the same information that the customer previously used to make its purchase decisions. Because the supplier has failed to incorporate the customer information into his PIC process, the supplier has lost an opportunity and the only change is who is carrying out the new process. A Type 1 relationship can be visualised in Figure 2. In principle the customer's inventory and sales information is available for the supplier to use in controlling his own production and inventory. But rarely do suppliers use this information for their PIC process in practice. Why is it that the information is not used to improve the PIC process?

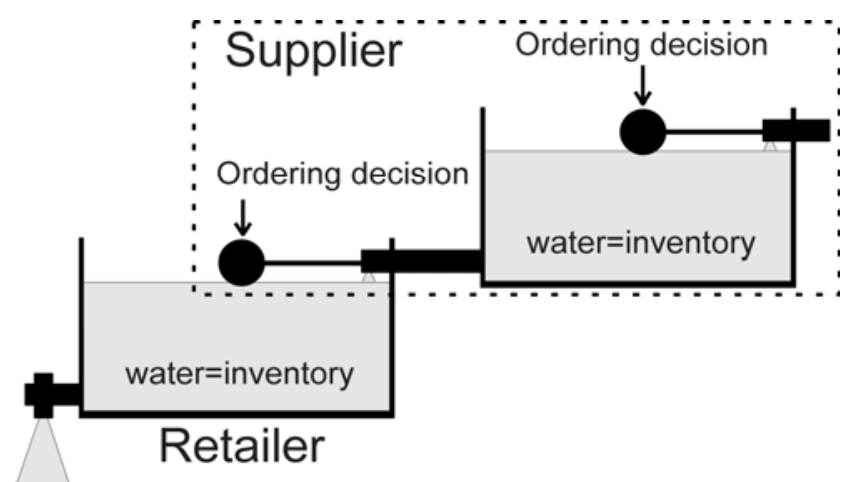

Figure 2. A Type I supply chain conceptualised by a water tank model

The challenge to exploit this valuable information provided through collaboration with the retailer is that this retailer is typically one of many requesting the supplier's products. Generating the replenishment order in the place of the customer's purchasing department is straightforward. It is much more difficult to set up a separate production and inventory management system to serve the customer. Setting up a separate PIC process for a customer which is not integrated with that of the rest of the supplier company - has consequences. More safety stocks, smaller production batches or longer intervals between production runs may be the result. 


\section{TYPE II: REPLENISHMENT AND FORECASTING}

Taking end customer sales into consideration when generating the forecast - even when complete visibility is not available - is easier than complete customer specific control processes. Figure 3 highlights the strategy. This step is frequently advertised as a key objective in VMI implementation projects, but is less frequently implemented. It is also a cornerstone of the Collaborative Forecasting, Planning and Replenishment (CPFR) strategy. What are the obstacles here?

The primary challenge is that the supplier needs to react to the replenishment order generated based on the customer's inventory situation. As a consequence an important obstacle for using Type II collaboration to improve a supplier's PIC process is that the benefit from incorporating visibility of end customer demand in the supplier PIC process is undermined by the need to respond to changes in customer inventory policy over time. Dejonckheere, Disney, Lambrecht and Towill (2003) have shown that bullwhip increases geometrically in Type 0 and Type I supply chains and linearly in Type II supply chains, so the potential benefits could be high.

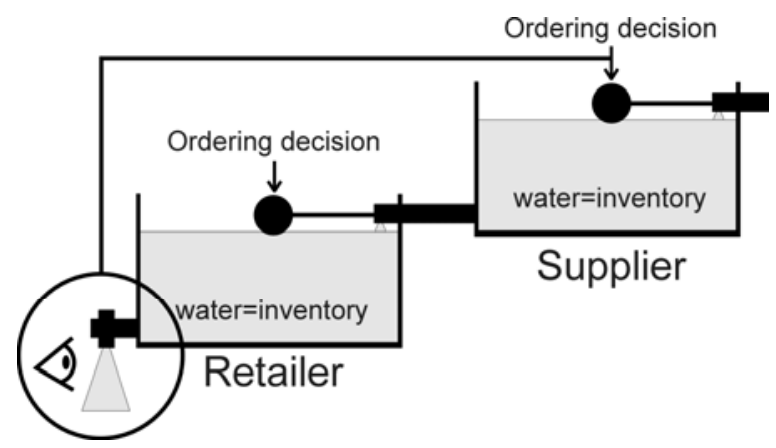

Figure 3. A Type II supply chain conceptualised by a water tank model

\section{TYPE III: REPLENISHMENT, FORECASTING AND CUSTOMER INVENTORY PLANNING}

There is a further piece of information in the supply chain that can be utilised to great benefit in the suppliers PIC process. That is information about the customers inventory position and it is important because control over the inventory management process of the customer can provide enough flexibility to avoid the bullwhip effect. The transition to the next level in the collaboration framework requires incorporating the customer inventory information, i.e. customer specific inventory management. The potential benefits for the supplier PIC performance derive from better control of both the replenishment and inventory management process one level down the supply chain. This makes it possible to use downstream requirements that are smoother than purchase orders generated based on a reorder rule. The principle is here illustrated using our water tanks models, Figure 4, based on a solution first proposed by Magee (1958).

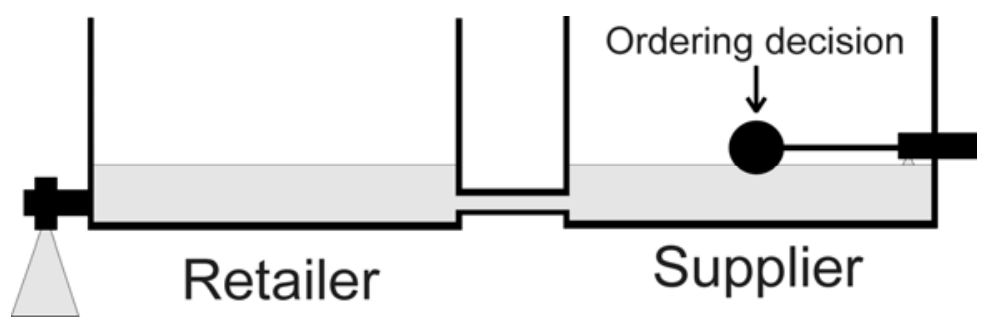

Figure 4. A Type III supply chain conceptualised by a water tank model 
Experience from real-world supply chains confirms that this levelling of requirements provides the supplier with more flexibility in choosing how to respond. In an example from the grocery supply chain the supplier gained between 2 and 3 weeks more time to respond to demand by considering customer specific requirements in the production and inventory control process (Kaipia et al, 2002). The benefit was more pronounced for the slower moving items in the product range.

\section{TYPE IV: REPLENISHMENT, FORECASTING, INVENTORY AND CUSTOMER DISTRIBUTION PLANNING}

In this type of supply chain configuration the supplier plans distribution on the customer level. This may be needed when there is a long transportation delay relative to stock cover at the customer, or where the products are perishable, see Figure 5.

How can the customer specific information be incorporated in the supplier's PIC in this type of collaboration configuration? This is more complicated than for the type III configuration. A brute force solution would be incorporating the new information in the suppliers PIC system by using a DRP (Distribution Requirements Planning) approach. Companies controlling their own distribution channels have refined and developed the approach to enable dynamic and continuous optimisation of the supply chain. Bookbinder and Heath (1988) developed the concept of DRP based on previous industrial work (e.g. Stenger and Cavinato, 1979). The goal is to minimise inventory and cost in the distribution system for a certain service level and demand forecast through a periodic - rolling schedule - planning of inventory levels and replenishments. In the collaborative supply chain configuration the supplier attempts to do the same based on information from customer controlled channels.

The primary problem with utilising a Type IV collaboration configuration is the periodic rolling schedule and long lead-times. The link between distribution requirements and supply disruptions lead to system nervousness. Additionally the costs for stock-outs, obsolescence for example, are not the same for supplier as for retailers. This leads to diverging interests and gaming, when making both demand forecasts and supply allocation decisions, Stevens (1989).

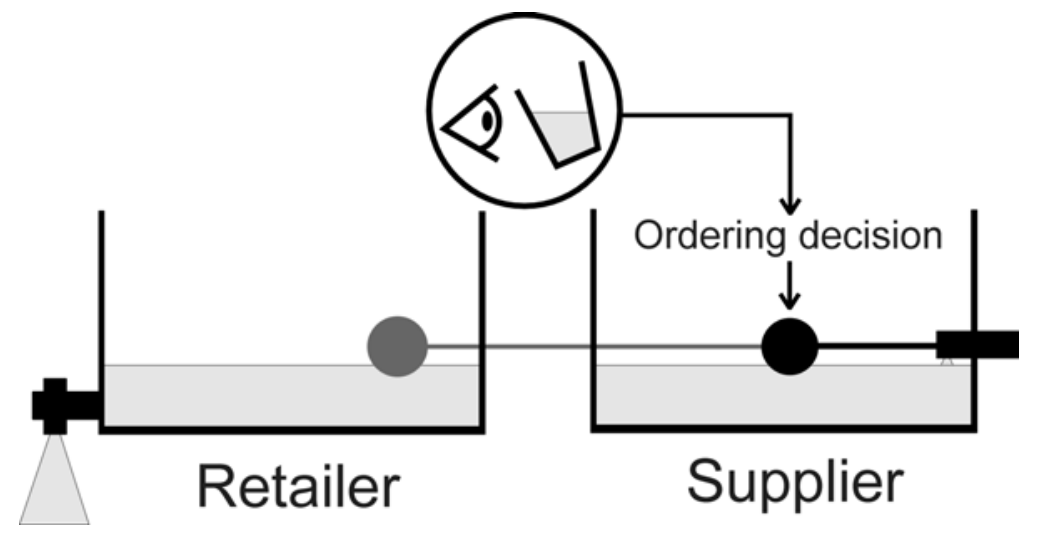

Figure 5. A Type IV supply chain conceptualised by a water tank model

\section{COLLABORATIVE SUPPLY CHAIN CONFIGURATIONS AND THEIR IMPLICATIONS FOR SUPPLIER PERFORMANCE}

Potentially the supplier can benefit greatly from incorporating customer demand, inventory and distribution requirements in his PIC process. The potential benefit is increased flexibility in scheduling production capacity and allocating scarce inventory. However, there are several serious obstacles in practice. 
Research on supply chain visibility efforts, such as VMI, rarely comments on the problems that arise when only part of the customer base are willing to share information. That is, when a company has to deal with several supply chain structures concurrently. Many of the most important contributions on supply chain visibility simply assume that all downstream data is always shared, but this is rarely the case, for example, see Table 2.

\begin{tabular}{|c|c|c|}
\hline Type of Data Made Available & In 1998 & Estimated 2001 \\
\hline Inventory and Capacity & $50 \%$ & $75 \%$ \\
\hline Demand History and Forecasts & $30 \%$ & $72 \%$ \\
\hline Order Status & $30 \%$ & $66 \%$ \\
\hline Project Design and Specifications & $34 \%$ & $54 \%$ \\
\hline Financial Information & $3 \%$ & $20 \%$ \\
\hline
\end{tabular}

Table 2: Percentage of large US companies making specific information available to business partners

(Price Waterhouse Coopers 1999 Survey Results Reported by Knolmayer et al, 2002)

Lee, Padmanabhan and Whang (1997), for example, suggest that retail data can be used to align forecasts in the supply chain, but assume that the information is always available from all retailers and they do not discuss how this should be done if some data is missing. This in effect would mean that to benefit in its own operations a company should move from a Type 0 or I configuration to a Type II in all customer relationships. Yu, Yan and Chen (2000) compare different levels of information sharing in the supply chain. Also in this case, the assumption is that comparable data is always available from all customers, i.e. that the supplier is able to change the supply chain configuration for all of its customers.

In the rare cases where partial information availability is discussed, the link to production planning and inventory control is still not explicitly examined. Waller, Johnson and Davis (1999), for example, use simulation to examine the effect of VMI adoption rates on inventory levels in a supply chain. The core of their VMI model, however, is increased inventory review and replenishment triggering frequency - the demand information available through VMI is not utilised in the model, i.e. no production planning and inventory control solution that would utilise the sell-through information available from the VMI-customers is presented.

Considering the link between collaborative supply chain configurations and supplier production and inventory control performance, it becomes clear that here is a significant gap in the literature. In practice, to benefit from collaboration the supplier PIC needs to be seamlessly integrated into a number of different collaborative or vendor managed supply chain configurations. Still, a majority of the research conducted examines situations in which information is available from all customers, or focuses on the relationship between one supplier and one customer. Real-life companies trying to benefit from partial visibility do not get much guidance from the existing literature.

\section{Acknowlegdements}

The Cardiff Young Researchers Initiative supported this research.

\section{REFERENCES}

Abernathy, F., Dunlop, J., Hammond, J., and Weil, D. (1999) "A Stitch in Time: Lean Retailing and the Transformation of Manufacturing - Lessons from the Apparel and Textile Industries", Oxford University Press, New York.

Bookbinder, J. and Heath, D. (1988) "Replenishment Analysis in Distribution Requirements Planning”, Decision Sciences, Vol. 19, No. 3, pp 477-489. 
Cachon, G. and Lariviere, M. (1999) "Capacity Choice and Allocation; Strategic Behaviour and Supply Chain Performance", Management Science, Vol. 45, No. 8, pp 1091-1109.

Carlsson, C and Fuller, R., (2000) "Fuzzy Approach to The Bullwhip Effect", Proceedings of the $15^{\text {th }}$ European Meeting on Cybernetics and Systems Research, Vienna, April 25-18, pp 228-233.

Childerhouse, P., Hermiz, R., Mason-Jones, R., Popp, A., and Towill, D.R. (2003) "Information Flow in Automotive Supply Chains Identifying and Learning to Overcome the Barriers to Change", Forthcoming in Industrial Management and Data Systems.

Dejonckheere, J., Disney, S.M., Lambrecht, M.R. and Towill, D.R., (2003), "The impact of information enrichment on the bullwhip effect in supply chains: A control engineering perspective", Forthcoming in the European Journal of Operational Research.

Disney, S.M. and Towill, D.R. (2002) "A Discrete Transfer Function Model to Determine the Dynamic Stability of a Vendor Managed Inventory Supply Chain", International Journal of Production Research, 2002, Vol. 40, No. 1, 179-204.

Geary, S., Childerhouse, P. and Towill, D.R. (2002) "Uncertainty and the Seamless Supply Chain", Supply Chain Management Review, July/Aug, pp 52-61.

Holmström, J. (1998) "Business Process Innovation in the Supply Chain: a Case Study of Implementing Vendor Managed Inventory", European Journal of Purchasing and Supply Management No. 4, pp 127-131.

Hoover, W.E. Eloranta, E., Holmström, J. and Huttunen, K (2001) "Managing the Demand Supply Chain: Value Innovations for Customer Satisfaction", Wiley and Sons.

Kaipia, R. , Holmström, J., and Tanskanen K. (2002), "What are you losing if you let your customer place orders?", Production Planning \& Control, Vol. 13, No. 1

Knolmayer, G., Merteus, P., and Zeier, A. (2002), "Supply Chain Management Based on SAP Systems", Springer-Verlag, Berlin.

Lapide, L. (2001) "New Developments in Business Forecasting", Journal of Business Forecasting Methods and Systems, Vol. 20, No. 4, pp 11, 12 and 36.

Lee, H.L. Padmanabhan, V., and Whang, S. (1997) "Information Distortion in a Supply Chain: The Bullwhip Effect”, Management Sciences, Vol. 43, No. 4, pp 546-558.

Magee, J.F., 1958, "Production planning and inventory control", McGraw-Hill Book Company, New York, pp. 80-83.

Mason-Jones, R. and Towill, D.R., (1997), "Information Enrichment: Designing the Supply Chain for Competitive Advantage", Supply Chain Management, Vol. 2 No. 4, pp 137-148.

Masters, J., Allenby, G. and LaLonde, B. (1992) "On the Adoption of DRP", Journal of Business Logistics, Vol. 13, No. 1. pp 47-67.

Metters, R., (1997) "Quantifying the bullwhip effect in supply chains", Journal of Operations Management, Vol. 15, pp 89-100.

Sabath, R., Autry, C. and Daugherty, P. (2001) "Automatic Replenishment Programs: The Impact of Organizational Structure" Journal of Business Logistics, Vol. 22, No. 1, pp 91106.

Stank, P., Keller, S. and Daugherty, P. (2001) "Supply Chain Collaboration and Logistical Service Performance”, Journal of Business Logistics, Vol. 22, No. 1, pp 29-49.

Stenger, A.J. and Cavinato, J.L. (1979), "Adapting MRP to the outbound side - Distribution requirements planning", Production and Inventory Management, Vol. 20, No. 4, pp. 1-13

Stevens, G., (1989), "Integrating the supply chain", International Journal of Physical Distribution and Logistics Management, Vol. 19, No. 8, pp3-8.

Yu, Z., Yan, H. and Cheng, T.C.E. (2000) "Benefits of Information Sharing with Supply Chain Partnerships", Industrial Management and Data Systems, Vol. 101, No. 3, pp 114119. 